\title{
Produção discursiva de uma política curricular organizada em ciclos: a criação do ciclo básico de alfabetização em Várzea Grande - MT
}

\author{
Eucaris Joelma Rodrigues Ferreira* \\ Ozerina Victor de Oliveira**
}

\section{Resumo}

Neste artigo problematizamos os tensionamentos entre o currículo por ciclos e o currículo por série no contexto da política curricular do município de Várzea Grande, MT. O objetivo do estudo é compreender as relaçóes de poder estabelecidas em processos de produção de políticas de currículo, considerando a coexistência de organizaçôes curriculares antagônicas. O aporte teórico-metodológico que fundamenta o estudo encontra-se pautado na compreensão da constituiçáo da política de currículo em um movimento cíclico (BALL; BOWE, 1992) e como discurso (LACLAU, 1986, 1996; MOUFFE, 2003). As consideraçôes sobre currículo organizado por ciclos e política curricular se fundamentam em Moreira (1990), Freitas (2003), Lopes (2005), Araújo (2006), Oliveira (2008), Mainardes $(2007,2009)$ e Silva (2010). O poder que permeia a disputa entre o currículo organizado por ciclos, aqui representado pelo Projeto de Reorganizaçáo do Ensino Fundamental e Implantação do Ciclo Básico de Alfabetização Cidadã e o currículo por série, é um movimento que acontece no interior da política curricular do município pesquisado. Esse movimento de poder permite que haja tensóes no campo curricular em busca da hegemonia pela universalidade de um único currículo apenas. O que esta pesquisa mostra é que essa busca se dá de modo constante, o que impossibilita afirmar a hegemonia desta ou daquela forma de organização curricular.

Palavras-chave: Currículo. Discurso. Relações de Poder.

\footnotetext{
* Mestre em Educaçáo pela Universidade Federal do Mato Grosso (UFMT). Doutoranda em Educação na Universidade Federal de Pelotas (UFPEL). Professora da Secretaria Estadual de Educaçáo do Estado de Mato Grosso.

** Doutora em Educação pela Universidade do Estado do Rio de Janeiro (UERJ). Professora no curso de Pedagogia e no Programa de Pós-Graduação em Educação da Universidade Federal do Mato Grosso (UFMT).
} 


\section{Currículo organizado por ciclos e tensionamentos}

Nas duas últimas décadas do século XX, a organização do currículo por ciclos de formação tem se constituído enquanto política de currículo em municípios e estados brasileiros (OLIVEIRA, 2008). Desde entấo, as redes públicas de ensino têm intensificado o convívio com diversas formas de organização curricular, entre elas, em especial, o currículo organizado por ciclos de formação ou aprendizagem e o currículo organizado por séries.

Já é notório saber, no campo do currículo, que as reformas não são lineares, não implicam a substituição de uma forma de organização curricular por outra e nem que as diferentes políticas de currículo convivam harmoniosamente (LOPES, 2005; BALL, 2005; OLIVEIRA, 2009). A partir dessa compreensão, perguntamos: como se dão as tensôes entre diferentes políticas de currículo em redes públicas de ensino no contexto de reforma curricular? Quais as disputas e negociaçóes entre currículos organizados por ciclos e currículos organizados por séries?

Tais perguntas emergem de e se direcionam a uma realidade específica. No caso, a política de currículo por ciclos desencadeada em Várzea Grande, município circunvizinho de Cuiabá, capital do estado de Mato Grosso. A primeira proposta curricular organizada por ciclos de formação na rede pública de ensino de Várzea Grande $^{1}$ foi criada em 2004, por meio do Projeto de Reorganização do Ensino Fundamental e Implantação do Ciclo Básico de Alfabetização Cidadã - Projeto CBAC (VARZEA GRANDE, 2004). Com essa delimitação geopolítica, indagamos: como ocorrem os tensionamentos entre a organização por ciclos e a organização seriada? Qual delas consegue se hegemonizar? Por quais caminhos ocorre a produção das tensões e da hegemonia?

O objetivo do estudo que ora apresentamos é compreender as relaçóes de poder estabelecidas em processos de produção de políticas de currículo, considerando a coexistência de organizaçôes curriculares antagônicas.

O aporte teórico-metodológico que fundamenta o estudo encontra-se pautado na compreensão da constituição da política de currículo em um movimento cíclico e como discurso. Compreensão ancorada na abordagem do ciclo de políticas (BALL; BOWE, 1992) e na teoria de discurso (LACLAU, 1986, 1996; MOUFFE, 2003).

Compartilhamos com a ideia defendida por Ball (2009) de que as políticas não são implementadas, pois elas não podem ser entendidas como um processo linear. Nesse sentido, as políticas curriculares se constituem ciclicamente pelos contextos, que "podem ser pensados de outra maneira e podem ser 'aninhados' uns dentro dos outros" (BALL, 2009, p. 306). 
Os currículos aqui analisados são compreendidos como discursos, por se configurarem em conjunto de posiçóes diferenciais (LACLAU, 1986) que lutam no campo curricular para hegemonizar seus ideais.

Nos limites deste artigo $^{2}$ apresentaremos os resultados do estudo documental, compreendendo os documentos como textos que consubstanciam uma política de currículo e que, por isso, têm papel importante em sua constituição cíclica. Sua importância está em que os documentos/textos materializam acordos passíveis de serem visualizados, identificados e/ou retomados após o momento de sua produçáo. Para o estudo documental, consideramos: o Plano Municipal de Educação (PME) (VARZEA GRANDE, 2003); Resolução no 006/05 do Conselho Municipal de Educação/Várzea Grande/Mato Grosso (CME/VG/MT) altera a Resolução no 003/04 (CME/VG/MT) (2004b), e normatiza a reforma curricular no município de Várzea Grande (2004a); o Projeto de Reorganização do Ensino Fundamental e Implantação do Ciclo Básico de Alfabetização Cidadã (Projeto CBAC) (VARZEA GRANDE, 2004b); a Declaraçáo de Cochabamba (UNESCO, 2001a) e a Declaração de Dakar (UNESCO, 2001b).

Ao abordarmos o currículo organizado por ciclos enquanto organizaçáo curricular, consideramos as contribuiçóes de estudiosos do campo curricular e de pesquisadores da referida forma de organizaçáo, tais como: Moreira (1990), Freitas (2003), Lopes (2005); Araújo (2006), Oliveira (2008), Mainardes (2007, 2009) e Silva (2010).

No propósito de compreender, a partir dos textos políticos, as relaçóes de poder entre o currículo organizado por ciclos e o currículo por série, observamos disputas em torno do significado e dos sentidos de currículo e de ciclos, equivalências entre projetos de diferentes âmbitos (local/nacional/global) na definição dos objetivos e metas de uma política de currículo e a configuração de uma identidade híbrida da política em análise.

Nas seçóes que seguem, apresentaremos as noçôes que orientam a análise e os dados que a consubstanciam.

\section{O Projeto CBAC: confrontos e confluência de discursos}

A década de 1990 foi o período em que políticas curriculares fundamentadas em ciclos emergiram no estado de Mato Grosso. Em 1996, a primeira proposta, o Projeto Terra, foi criada pela Secretaria de Educação (SEDUC) em algumas escolas rurais, com o objetivo de manter a integraçáo entre homem e campo, propondo uma forma diferente de organização do ensino, fazendo adequaçóes entre a escola e a realidade da comunidade local (ARAÚJO, 2006). 
Em 1999, na rede pública municipal de Cuiabá, foi oficializada a Escola Sarã, que teve as primeiras experiências desde 1995. A Escola Sarã entende os ciclos de formaçáo como um modo de organizar o tempo escolar, que visa: superar a divisáo estanque do currículo, na perspectiva de respeitar o processo de construçáo de conhecimentos dos alunos; flexibilizar os processos de ensino; e, em especial, conceber a avaliação de modo processual. Nela, o ensino fundamental encontra-se organizado em três ciclos de formação: o primeiro caracteriza a fase da infância e recebe alunos na faixa etária de 6 a 9 anos; o segundo caracteriza a fase da pré-adolescência e recebe alunos na faixa etária de 9 a 12 anos; e o terceiro caracteriza a fase da adolescência, recebendo alunos de 12 a 15 anos (OLIVEIRA, 2008).

No ano de 1999, na perspectiva de ampliar o Projeto Terra, a rede de ensino pública estadual de Mato Grosso oficializa a Escola Ciclada, como proposta de organização em ciclos de formação, criando o Ciclo Básico de Alfabetização e definindo os seguintes critérios de enturmação: idade; desenvolvimento afetivo, cognitivo e sóciohistórico-cultural; e histórico escolar (ARAÚJO, 2006).

Em 2004, o município de Várzea Grande teria sua primeira proposta curricular organizada em ciclos, criada por meio do Projeto CBAC (VARZEA GRANDE, 2004b). Este projeto foi pensado a partir de dois documentos, o Plano Municipal de Educação (VARZEA GRANDE, 2003) e do projeto Escola Cidadã Guaná: uma escola de comunidade ${ }^{3}$, que diagnosticaram problemas que acometiam o fracasso escolar no município.

Entre os problemas expostos no PME, encontram-se os altos índices de reprovação e evasão escolar no Ensino Fundamental da rede municipal: "Em Várzea Grande, os maiores problemas vivenciados no Ensino Fundamental náo fogem à regra daqueles enfrentados pelos demais municípios brasileiros, quais sejam: a defasagem série/idade, o alto índice de reprovação e o abandono por desistência dos estudos" (VARZEA GRANDE, 2003, p. 76).

No enfrentamento desses problemas, construiu-se o projeto Escola Cidadá Guaná, voltado, mais especificamente, para uma reestruturação curricular:

[...] este projeto foi elaborado pela equipe da Secretaria de Educação e Cultura no período compreendido entre 20012004. A partir das discussóes coletivas desencadeadas no interior da Secretaria Municipal de Educação e Cultura (SMEC) e das Escolas, foi designado um grupo de redação que interpretou e organizou as ideias coletivas sistematizando o documento. (SILVA, 2010, p. 266). 
Ao estabelecer essas relações entre os referidos documentos, depreendemos que o Projeto CBAC (VARZEA GRANDE, 2004b) foi construído como desdobramento do PME (VARZEA GRANDE, 2003) e do projeto Escola Cidadã Guaná, com o intuito, em especial, de melhorar os índices de rendimento na educação pública municipal. Sua realização trouxe várias mudanças nos currículos das escolas dessa rede municipal.

$\mathrm{Na}$ análise dessas mudanças, destacamos dois movimentos impulsionadores das relaçóes de poder: um movimento de equivalência de sentidos entre os âmbitos local e global, e entre nacional e local; e um movimento de confronto entre os significados e sentidos de currículo e de ciclo.

Por meio dos objetivos e metas do Projeto CBAC e de fundamentos da proposta de Educaçáo para Todos, expressa em documentos, como a Declaração de Dakar $(U N E S C O, 2001 b)^{4}$ e a Declaração de Cochabamba (UNESCO, 2001a), perpassam a relaçáo local/global. Vejamos como isso se confirma, relacionando-se os objetivos do Projeto CBAC e alguns trechos das Declaraçóes.

Por parte do Projeto CBAC, encontram-se entre os objetivos e metas:

Iniciar o rompimento com a estrutura lógica de organizaçáo escolar seriada, oferecendo uma formaçáo que assegure, acima de tudo, ao aluno em fase de alfabetização, o direito à inclusáo. (VARZEA GRANDE, 2004b, p. 12, grifos nosso).

Implantar o Ciclo Básico de Alfabetizaçáo Cidadã - CBAC, destinado ao atendimento dos alunos de seis a oito anos com vistas a assegurar maior flexibilidade na organizaçáo dos tempos e espaços escolares em 100\% das escolas do Sistema Público Municipal de Ensino. (VARZEA GRANDE, 2004b, p. 12, grifos nosso).

Os sentidos que aparecem nos objetivos sinalizam para romper com o currículo organizado em série, garantir um direito fundamental e para flexibilizar espaços e tempos escolares. Sentidos semelhantes são encontrados nos documentos de âmbito global:

[...] os sistemas educacionais precisam apressar o ritmo da sua transformação, de modo a não se atrasarem em relação às mudanças que ocorrem em outras esferas da sociedade e a conduzirem a um salto qualitativo na educação. Os esforços que estão sendo enviados presentemente em favor da mudança sistemática, por meio de reformas na educaçáo, terão pouca utilidade se não houver também uma mudança nos atores e 
processos educacionais. Isto significa que precisamos focalizar nossa atençáo na qualidade das práticas de ensino, vinculando-as a mudanças na administração escolar e aprimorando essas práticas e os seus resultados, de forma a facilitar a criaçáo das condiçóes necessárias para que as escolas se tornem ambientes adequados de aprendizado para os estudantes. (UNESCO, 2001a, grifos nosso).

Melhorar todos os aspectos da qualidade da educaçáo e assegurar excelência para todos, de forma a garantir a todos resultados reconhecidos e mensuráveis, especialmente na alfabetização, na aquisição de conhecimentos matemáticos e habilidades essenciais à vida. (UNESCO, 2001b, grifos nosso).

[...] que se faz necessário um novo tipo de escola. É absolutamente essencial que as escolas sejam mais flexíveis e altamente sensíveis aos desafios, e que tenham uma efetiva autonomia pedagógica e administrativa. A elas deve ser dado o apoio suficiente que as capacite a organizar e desenvolver seus próprios projetos educacionais em resposta às necessidades e à diversidade da comunidade a que servem, projetos os quais sáo elaborados coletivamente, e a assumir juntamente com as entidades governamentais e outros atores a responsabilidade pelos resultados. Isso exige que os governos proporcionem recursos financeiros, humanos e materiais a todas as instituiçóes educacionais a eles jurisdicionadas, orientando-as para os segmentos mais pobres da populaçáo. (UNESCO, 2001a, grifos nosso).

A proximidade de sentidos entre estes documentos remete à relação entre o local/global que configura o discurso da política em análise, especialmente quando se observa que alguns objetivos e metas do documento local se encontram conectados aos fundamentos de documentos internacionais. Em relação a isso, Ball (2001, p. 102) explica que a criação de novas políticas nacionais é um processo de "bricolagem" que se configura em um contínuo processo de empréstimo, cópias e parte de ideias de outros contextos.

Os sentidos dessa relação indicam que, menos por uma relação de determinação vertical entre o global e o local e mais por influência do contexto histórico, há uma confluência de interesses entre os dois âmbitos que os constitui mutuamente. Assim, as políticas curriculares, mesmo quando se apresentam como locais, trazem configurações e tendências que as colocam em consonância com políticas globais.

Enquanto na relação dos âmbitos local e global encontramos a confluência de sentidos políticos, na relação entre os âmbitos local e nacional encontramos a identidade teórica da política de currículo em análise. 
No contexto do Projeto CBAC, entendido não somente como restrito ao texto do documento, mas incluindo seu processo de elaboração, confirma-se a presença dos princípios da pedagogia progressista de Paulo Freire, por meio do documento da Escola Cidadã Guaná ${ }^{5}$ que, por sua vez, teve sua elaboração assessorada pelo Instituto Paulo Freire ${ }^{6}$ :

[...] o projeto [CBAC] foi elaborado tendo por paradigma os princípios e fundamentos da Escola Cidadã Guaná: [...] proposta de Gestáo Municipal e Escolar, assumida pelo Sistema Público de Ensino de Várzea Grande, cujo objetivo é a construção de uma cultura escolar humanizadora e transformadora, através da ampliação das vivências curriculares para além dos conteúdos disciplinares, da melhoria da qualidade do processo ensino-aprendizagem, da melhoria na aplicaçáo dos recursos públicos e do aumento da equidade social. Tal proposta pretende alcançar esse objetivo desenvolvendo a capacidade de administraçáo colegiada ou de gestáo participativa tanto no âmbito da Secretaria de Educação como das escolas, criando condiçôes para adequada construção de uma escola de nova qualidade: participativa, aprendente, prazerosa, mas, sobretudo humana e transformadora. Programa de Gestáo Municipal e Escolar/ Instituto Paulo Freire. (VARZEA GRANDE, 2004b, p. 3).

O excerto citado anteriormente evidencia a relação local/nacional, a qual sinaliza que os pressupostos teóricos do Projeto CBAC encontram-se fundamentados no projeto Escola Cidadã Guaná, que indicam a identidade teórica do CBAC com o pensamento de Paulo Freire.

O Projeto de Escola Cidadã desenvolveu-se na década de 1980, durante a gestão de Paulo Freire ${ }^{7}$ na Secretaria de Educação no município de São Paulo, através do movimento de educação popular, e foi amplamente divulgada com seus princípios de ser estatal, quanto ao financiamento, comunitária e democrática, quanto à gestáo, e pública, quanto à destinação.

$\mathrm{Na}$ explicitação do aporte teórico da política em análise, faz-se necessário esclarecer qual modalidade de Ciclos compóe o Projeto CBAC. A criaçáo do Projeto implicou na reorganizaçáo do Ensino Fundamental. Este passou a ter duas diferentes formas de organização curricular, normatizadas pela Resolução no 003/04 CME/VG/MT, que instituiu "nas Unidades Escolares do Sistema Municipal de Ensino, um Regime Misto de Organizaçáo Escolar", sendo que "os 03 (três) primeiros anos do Ensino Fundamental será organizado pelo Regime de Ciclos", e "do $4^{\circ}$ ao $9^{\circ}$ ano do Ensino Fundamental será organizado pelo Regime Seriado [...]"8 (VARZEA GRANDE, 2004a). A justificativa sobre essa organização curricular é sustentada pela 
[...] preocupação de se evitar os equívocos cometidos por alguns Estados e Municípios brasileiros, quando, no seu processo de reorganizaçáo do ensino, implantaram o Regime de Ciclos de forma generalizada no Ensino Fundamental, impedindo com isto, a possibilidade de um acompanhamento mais criterioso e, o que é pior, a necessária e indispensável formação dos profissionais da educação para a nova sistemática de organização do ensino. (VARZEA GRANDE, 2004b, p. 8).

No entanto, tal justificativa não nos parece suficiente, requerendo a busca de questôes mais substantivas. Para isso, consideramos o posicionamento do Projeto CBAC em relação à progressão dos alunos no decorrer de escolarização:

Náo haverá retençáo de alunos durante o Ciclo; [...] Ao final do Ciclo Básico de Alfabetização Cidadá, o aluno deverá ter desenvolvido as habilidades/saberes - ler, escrever, produzir textos, interpretar, resolver problemas e pesquisar para sua promoçáo. A promoçáo para o $4^{\circ}$ ano do Ensino Fundamental dos alunos ainda com dificuldade de aprendizagem será de responsabilidade do Conselho do Ciclo. No final do $3^{\circ}$ ano do Ciclo poderá o aluno ficar retido. Essa retenção só será efetivada após discussão, análise e avaliação do Conselho do Ciclo. A avaliação do aluno deverá levar em conta todo seu processo de desenvolvimento. (VARZEA GRANDE, 2004b, p. 36, grifos nosso).

Observa-se que o desenvolvimento de algumas habilidades e saberes disciplinares se constitui em critério definidor de retenção ou promoção, o que vem caracterizar uma das modalidades de organização curricular em ciclos, os ciclos de aprendizagem.

Alguns estudiosos, como Mainardes (2007) e Fetzner (2007), indicam a existência de diferenças nas propostas de organização curricular por ciclos. No Brasil temos a identificação de duas formas: os ciclos de aprendizagem e os ciclos de formaçáo.

Os ciclos de aprendizagem pautam-se no nível de aprendizagem dos alunos para a enturmação e a promoção dos mesmos. Nesse caso, o aluno pode ser retido/reprovado no final de cada ciclo quando não atingir os objetivos específicos daquele ciclo. Nessa modalidade, o ciclo é organizado em períodos de dois ou três anos (MAINARDES, 2007; FETZNER, 2007)

Para Mainardes (2007), as propostas de ciclos de aprendizagem geralmente visam promover rupturas menos radicais no que se refere ao currículo, à avaliação, à metodologia e à organização. $\mathrm{O}$ autor ainda destaca que algumas propostas de ciclos de 
aprendizagem têm levado em consideração características utilizadas em outros lugares e em outras formas de organização curricular, o que justifica a preocupação presente no Projeto CBAC em se restringir aos três primeiros anos do Ensino Fundamental.

Em relação à proposta de ciclos de formação, esta se fundamenta nos ciclos de desenvolvimento humano (infância, puberdade e adolescência), com base em teorias psicológicas do desenvolvimento humano, em uma perspectiva antropológica. Nessa proposta, não há reprovação dos alunos ao longo do Ensino Fundamental, sendo sua reestruturação curricular mais profunda e "algumas experiências, metodologias específicas são definidas (no Projeto Escola Plural, projetos de trabalhos; na Escola Cidadã, complexos temáticos)" (MAINARDES, 2007, p. 73).

A partir das consideraçóes de Mainardes (2007), entendemos que o Projeto CBAC, ao propor a organização do ciclo em três anos, permitindo ou não a retenção no final de cada ciclo, apresenta como fundamento predominante a proposta de Ciclos de Aprendizagem. O que nos parece discursivamente bastante negociável com a organização curricular organizada por série, uma vez que esta usa critério semelhante para a progressão dos alunos no transcorrer da escolarização.

Sendo os Ciclos de Aprendizagem a principal característica da organizaçáo curricular defendida no Projeto CBAC, buscamos compreender qual sentido político se apresenta com maior ênfase em sua defesa. Nela encontramos um grande investimento em criticidade, redefinição de concepçóes, busca de qualidade de ensino, luta por hegemonia e democracia, conforme consta no próprio documento:

[...] os Ciclos necessariamente devem abrir-se para a vida real. Devem abrir-se criticamente para todas as dimensóes possíveis do trabalho dentro e fora da escola, ser um estruturador de outras relaçóes de poder entre as pessoas e entre as pessoas e coisas. (VARZEA GRANDE, 2004, p. 15, grifo nosso).

[...] os Ciclos exigem uma reconversáo cultural da escola, com nova estrutura e novas concepçóes de currículo, de conhecimento, de avaliaçáo, de gestão e de princípios de convivência, porque o ensino por ciclos náo é tão somente um ajuntamento de séries, e sim a organizaçáo a partir do desenvolvimento humano. (VARZEA GRANDE, 2004b, p. 17 , grifo nosso).

A estrutura por Ciclo leva também a um enfrentamento sério da questáo do fracasso escolar, através de uma perspectiva educacional onde existe o respeito, o entendimento e a investigação sobre os processos sócio-cognitivos de 
produção de conhecimento pelos quais passa cada educando. (VARZEA GRANDE, 2004b, p.14, grifo nosso).

[...] sendo o regime de ciclos organizado em uma outra lógica - a das fases do desenvolvimento humano - e náo através de uma lógica propedêutica de hierarquizaçáo dos conhecimentos, ele náo pode funcionar com os critérios da seriaçáo. (VARZEA GRANDE, 2004b, p. 16, grifo nosso).

[...] o Ciclo de Formaçáo, ao exigir uma proposta mais global na redefiniçáo de tempos e espaços escolares, compreendendo seus aspectos pedagógicos, administrativos e políticos - inclusive, compreendendo a escola - numa visão freireana - de espaço de contra hegemonia - possui maiores possibilidades de ser entendido, sobretudo pelos educadores, de forma positiva, não como uma mera soluçáo pedagógica para o desempenho escolar dos alunos, mas sim, como um longo e necessário processo de resistência [...]. (VARZEA GRANDE, 2004b, p. 9, grifos nosso).

Nos sentidos dados aos argumentos que procuram sustentar a organização curricular por ciclos de formação, a exemplo dos excertos citados, há predominância da tendência curricular crítica nos fundamentos e na função dada ao currículo organizado em ciclos.

As atribuiçóes à palavra "ciclos" conduzem o currículo para uma função de estruturador de forças num movimento de resistência, de contra-hegemonia, que deve se desenvolver nas unidades escolares.

Assim, o Projeto CBAC traz em seus discursos a predominância de fundamentos da tendência da educação popular, que, segundo Moreira (1990, p. 174), enfatiza a criação de conhecimentos revolucionários na escola. E os ciclos, sendo vistos como processo de resistência (FREITAS, 2003), valorizam o grau de mobilização social. Isso também pode ser confirmado pela contraposição à lógica excludente do currículo seriado. A criação do currículo organizado em ciclos se justifica, segundo Mainardes (2009), como real possibilidade de construção de uma escola democrática, não seletiva, não excludente e que poderia garantir a todos os alunos o direito de permanecer e aprender na escola. Na mesma perspectiva, Araújo (2006) nos diz que os ciclos de formaçáo colocam em xeque o modelo de organização escolar seriada, por ultrapassar os tempos de série organizados em blocos, possibilitando um tempo maior para o aluno que necessita dele para aprender.

Também visualizamos uma concepção de sociedade de tendência crítica fundamentando o Projeto CBAC. Esta é compreendida como estruturada pela ordem 
capitalista, promovendo a exclusão social. Portanto, há uma preocupação com a exclusão que é reproduzida e produzida na escola.

Por isso, a necessidade e preocupação de promover, através de uma proposta curricular, uma educação contra-hegemônica que transforme e modifique as condições e relaçóes sociais estabelecidas, ao longo do tempo, pelos condicionantes econômicos. Desse modo, o currículo configura-se em espaço de poder, porque, visualizando a hegemonia de uma proposta curricular, também se visualiza a possibilidade de contestá-la, contrapondo outras propostas curriculares.

Nesta seção, destacamos, ainda, os significados de currículo que permeiam a proposta analisada. Por um lado, o Projeto CBAC concebe o currículo como:

[...] fenômeno histórico, resultado de forças sociais, políticas, pedagógicas e culturais que expressam a organizaçáo dos saberes, vinculados à construçáo dos sujeitos. Currículo é concebido como processo dinâmico, mutável, sujeito a inúmeras influências, aberto e flexível referente a uma proposta político-pedagógica que explicita e revela sempre graus diferenciados do compromisso da escola com o social, a história e a cultura. (VARZEA GRANDE, 2004b, p. 17, grifo nosso).

Em termos de sua construção, defende:

[...] que as Propostas Curriculares das Escolas Municipais, só poderão ser, de fato, organizadas pelos sujeitos profissionais da educaçáo e alunos - que nela estáo envolvidos, a partir de sua prática e de sua reflexáo sobre ela, construindo a partir daí o Currículo Vivo do Ciclo [...]. (VARZEA GRANDE, 2004b, p. 20, grifo nosso).

No que diz respeito à organização do conhecimento, argumenta:

[...] a abordagem intertransdisciplinar e globalizada proporcionará o enriquecimento da ação educativa. A organizaçáo dos conteúdos deverá ser norteada por ela, cabendo às escolas definirem a metodologia mais coerente com a proposta definida (tema gerador, projetos, eixos temáticos, centros de interesse, atividades significativas), devendo, contudo, ser compromisso de todas as áreas do conhecimento, o desenvolvimento das habilidades da leitura, da escrita, da interpretaçáo, da produçáo de textos, resolver problemas e pesquisar [...]. (VARZEA GRANDE, 2004b, p. 20 , grifos nosso). 
Quanto às suas finalidades, entende que:

[...] este currículo alicerçado em princípios sólidos deverá promover ao agir pedagógico as possibilidades criativas, desafiadoras, de autodescoberta, de estímulos e de trabalhos científicos, direcionando a construçáo do conhecimento e a conquista de movimentos que signifiquem para o educando os primeiros passos para a busca de sua autonomia, como agente de sua própria história e sujeito ativo na construçáo de seu saber. [...] Queremos que a escola propicie a experiência profunda e total da cidadania para todos [...]. (VARZEA GRANDE, 2004b, p. 19, grifo nosso).

Por outro lado, contraditoriamente ao defendido em termos de concepção, organização do conhecimento e finalidade, estabelece uma relação de dependência com projetos de âmbito nacional:

[...] além dos referenciais da Escola Guaná à realidade de cada ciclo, uma outra adequaçáo faz-se também necessária, qual seja a do Referencial Curricular Nacional para a Educaçáo Infantil ( no que diz respeito às crianças de seis anos) e dos Parâmetros Curriculares Nacionais para o Ensino Fundamental de onde poderáo ser retirados os conteúdos e objetivos específicos indispensáveis ao desenvolvimento cognitivo dos alunos (de sete e oito anos), que deveráo ser trabalhados de acordo com as necessidades colocadas pelos Temas Geradores ou pelos Projetos eleitos pela Unidade Escolar para serem trabalhados no Ciclo. (VARZEA GRANDE, 2004b, p. 20, grifos nosso).

Esses excertos do texto em análise situam "ciclos" no campo curricular, que se pode considerar como "misto". E aqui se utiliza da mesma palavra usada na Resolução 003/04 - CME/VG/MT (VARZEA GRANDE, 2004a) para classificar a existência de uma política curricular que contempla duas propostas curriculares diferenciadas nas escolas municipais.

Não nos parece impossível fixar o significado de currículo do Projeto CBAC, uma vez que se tem uma mescla de identidades curriculares que foram sendo associadas na composição da política curricular em análise. Esse discurso contempla, ao mesmo tempo, variaçóes e ambivalências curriculares. No momento em que se é aberto/flexível, orienta de onde podem ser retirados os conteúdos e objetivos específicos, indispensáveis à aprendizagem. Esse lugar, ao qual se deve recorrer, não é um lugar qualquer, o que possibilita a retomada das consideraçóes de Ball (1994 apud 
MAINARDES, 2007, p. 37), de que "os textos são produtos de influência e intenções dentro do processo de formulação da política".

Ao utilizarmos o termo "misto", foi só um ligeiro incômodo, causado pelo impacto de tanta diferença. Outra possibilidade de se compreender o uso da palavra "misto", nesse contexto, seria entender que:

[...] nas atuais políticas de currículo no Brasil, as mesclas entre construtivismo e competências; currículo por competências, currículo interdisciplinar ou por temas transversais e currículo disciplinar; valorização dos saberes populares, dos saberes cotidianos e dos saberes adequados à nova ordem mundial globalizada são exemplos de construçôes híbridas que não podem ser entendidas pelo princípio da contradição. (LOPES, 2005, p. 57).

Nesse sentido, diante do aspecto prescritivo dos Parâmetros Curriculares e do aspecto libertador dos Temas Geradores, visualizamos que a constituição do próprio Projeto CBAC se configura por relaçóes de força que expressam "[...] um currículo mesclado por conceitos e ideias de habilidades, competências, com influências dos pressupostos da educação defendidos pela UNESCO - Pilares da educação; com a educação popular política e libertadora de Paulo Freire; [...]" (SILVA, 2010, p. 267).

Isso nos parece instigante, porque as relaçóes de poder não se caracterizam apenas externamente, entre a luta que é travada pelos currículos em ciclos e seriado, que compõem a organização curricular híbrida do município, mas as relaçôes se constituem internamente na identidade de cada modalidade de organização curricular.

As diferenças curriculares presentes no Projeto CBAC se constituem em relaçôes de poder, que se configuram a partir do entendimento destacado por Mouffe (2003), de que o poder não deve ser concebido como uma relação externa, que aconteça entre duas identidades pré-constituídas, mas antes como constituinte das próprias identidades.

Todo o contexto social em que o Projeto CBAC foi criado é caracterizado como um período de significativas reformas educacionais em nosso país. Foi também uma das finalidades do referido projeto reformar o sistema municipal de educação de Várzea Grande. E isto não se justifica em somente oportunizar mudanças no contexto curricular, até porque, reforma e mudanças possuem sentidos diferentes. Oliveira (2008) esclarece que reforma não é sinônimo de mudança, de modo que, se definirmos o significado de mudança, não esclareceremos o significado de reforma. Nesse sentido, reforma tem um sentido amplo, sendo compreendida como uma prática que estabelece prioridades e posiçóes para e por protagonistas de uma política curricular. 
Toda a análise nos leva a crer que a política de currículo, materializada no Projeto CBAC, com suas divergências e confluências internas e externas, configura-se em uma constante prática de se estabelecer prioridades e articulaçóes que, ora colocam os ciclos de formação em uma posição favorável, ora colocam a organização seriada em outra posição; ora fortalecem o sentido de mudança, ora mantêm relaçóes de poder já estabelecidas.

\section{Algumas considerações}

Ainda que pareça que o espaço da política curricular seja limitado ou delimitado pela existência de duas formas de organização curricular, isto toma sentido mais amplo quando as diferentes formas de organização são compreendidas como discurso conjunto de posiçôes diferenciais - que lutam no campo discursivo para hegemonizar seus ideais (LACLAU, 1986).

A partir das consideraçóes laclaunianas, compreendemos que, nesse embate, nenhuma das formas de organização curricular se encontra imune às açốes da outra, havendo assim um movimento que tenta estabelecer conexôes variáveis e contingentes entre ambas. Embate que se evidencia com a simples presença de ambas as organizaçóes, o ciclo e a série, e também nos argumentos que dáo sustentação ao discurso em prol dos ciclos: o currículo por ciclo não se afirma sozinho, precisa, para tanto, constantemente recorrer ao currículo seriado, contrapondo-se ao mesmo. A defesa dos ciclos de aprendizagem também não se sustenta por si só, pois constantemente recorre ao desenvolvimento humano como base definidora do currículo. Tal relaçáo de poder parece negociada por um reconhecimento mútuo, a primeira como demanda emergente e a segunda por tudo que tem sido construído ao longo dos anos nos sistemas educacionais. Assim, entendemos e compartilhamos com o pensamento laclauniano, de que nesta situação, a concepção tradicional e racional, "em que o poder foi inteiramente eliminado" (LACLAU, 1996, p. 177, tradução nossa), não se faz presente na política curricular em análise.

$O$ poder que permeia a disputa entre o currículo organizado por ciclos, aqui representado pelo Projeto CBAC, e o currículo por série, é um movimento que acontece no interior da política curricular do município de Várzea Grande, MT. Esse movimento, de poder, permite que haja tensôes no campo curricular em busca da hegemonia pela universalidade de um único currículo apenas. O que esta pesquisa nos mostra é que essa busca se dá de modo constante, o que nos impossibilita afirmar a hegemonia desta ou daquela forma de organização curricular. 


\section{Notas}

${ }^{1}$ G1 Em 2011 o município de Várzea Grande contava com 75 escolas municipais; 50 escolas eram de ensino fundamental e correspondiam a 13.934 matrículas. Informação disponível em: <http://portal.inep.gov.br/indicadores-educacionais>. Acesso em: 07/01/2014.

2 Este artigo apresenta uma reelaboração parcial da dissertação de mestrado de Eucaris Joelma Rodrigues Ferreira (2011), intitulada A Emancipação nas Relaçôes de Poder em um Currículo Organizado em Ciclos, defendida em 2011 no Programa de Pós Graduação em Educação/IE/UFMT.

3 "Consiste na leitura de mundo via transposição de dados e fatos como indicadores nas diferentes dimensóes da realidade escolar. [...] Marco definidor na política educacional municipal por conceber o seu fazer educativo o enfoque à cidadania" (VARZEA GRANDE, 2003, p. 17;24).

${ }^{4}$ A Conferência de Dakar "compreendeu primeiramente a avaliação feita em cada país, seguida no continente por uma conferência preparatória (Conferência Regional de Educação para Todos nas Américas, República Dominicana, fevereiro de 2000) e, finalmente, pela convocação do Fórum Mundial sobre Educação de Dakar em abril de 2000. [...] As conclusões da Conferência Regional de Santo Domingo e as do Fórum Mundial de Dakar representam marcos importantes na luta pela universalização da educação básica, compreendida como elemento central na conquista da cidadania. Por sua relevância social e pública estabeleceu-se a parceria entre a UNESCO Brasil [...]" (UNESCO, 2001b).

5 "Guaná se refere ao nome da tribo indígena, os primeiros habitantes da região, que assim se denominavam por se compararem aos pássaros existentes na região" (VARZEA GRANDE, 2003, p. 24).

6 "A Secretaria Municipal de Educação e Cultura de Várzea Grande é uma das instituições que estabelece parceria ao Instituto Paulo Freire”. Disponível em: <http://www.paulofreire.org>. Acesso em:07/01/2014.

7 "Paulo Freire tornou-se em 1989 Secretário de Educação no Município de São Paulo. Durante seu mandato, fez um grande esforço na implementação de movimentos de alfabetizaçáo, de revisão curricular e se empenhou na recuperação salarial dos professores". Disponível em: <http://www.paulofreire.org >. Acesso em:07/01/2014.

8 A Resolução no 003/04/CME/VG fora alterada pela Resolução no 006/2005/CME/VG (VARZEA GRANDE, 2005). Acesso em: 07/01/2014. 


\section{REFERÊNCIAS}

ARAÚJO, Marisa Inês Brescovici. Resistência docente à escola ciclada. Brasília, DF: Liber Livro, 2006.

BALL, Stephen J. Profissionalismo, gerencialismo e performatividade. Cadernos de Pesquisa, São Paulo, v. 35, n. 126, p. 539-564, set/dez. 2005. Disponível em: <http://www.scielo.br/pdf/cp/v35n126/a02n126.pdf>. Acesso em: 7 jan. 2014.

BALL, Stephen J. Um diálogo sobre justiça social, pesquisa e política educacional. Entrevista concedida a Jefferson Mainardes e Maria Inês Marcondes. Educação \& Sociedade, Campinas, SP, v. 30, n. 106, p. 303-318, jan./abr. 2009. Disponível em: <http://www.scielo.br/pdf/es/v30n106/v30n106a15.pdf>. Acesso em: 7 jan. 2014.

BALL, Stephen J; BOWE, Richard. Subject departments and the 'implementation' of National Curriculum policy: an overview of the issues. Journal of Curriculum Studies, v. 24, n. 2, p. 97-115, 1992.

FERREIRA, Eucaris. Joelma Rodrigues. A emancipação nas relaçōes de poder em um currículo organizado em ciclos. 2011. 110 f. Dissertação (Mestrado em Educação) Universidade Federal de Mato Grosso, Cuiabá, 2011.

FETZNER, Andréa Rosana. Educação popular, organização do ensino e ciclos: alguns desafios escolares. In: FETZNER, Andréa Rosana (Org.). Ciclos em Revista: implicaçôes Curriculares de uma Escola Não Seriada. Rio de Janeiro: Wak, 2007. v. 2. $128 \mathrm{p}$.

FREITAS, Luiz Carlos de. Ciclos, seriação e avaliação: confrontos de lógicas. São Paulo: Moderna, 2003.

LACLAU, Ernesto. Os novos movimentos sociais e a pluralidade do social. Revista Brasileira de Ciências Sociais, São Paulo, v. 1, n. 2, out. 1986. Disponível em: $<$ http://www.anpocs.org/portal/index.php?option=com_content\&view=article\&id= 235:rbcs-02\&catid=69:rbcs\&Itemid=399>. Acesso em: 3 dez. 2013.

LACLAU, Ernesto. Emancipación y diferencia. Buenos Aires: Ariel, 1996.

LOPES, Alice Ribeiro Casimiro. Política de currículo: recontextualização e hibridismo. Currículo sem Fronteiras, v. 5, n. 2, p. 50-64, jul./dez. 2005. Disponível em: <http://www.curriculosemfronteiras.org/vol5iss2articles/lopes.pdf>. Acesso em: 22 nov. 2013.

MAINARDES, Jefferson. Reinterpretando os ciclos de aprendizagem. São Paulo: Cortez, 2007. 
MAINARDES, Jefferson. A escola em Ciclos: fundamentos e debates. São Paulo: Cortez, 2009.

MOREIRA, Antônio Flávio Barbosa. Currículos e Programas no Brasil. Campinas, SP: Papirus, 1990.

MOUFFE, Chantal. Democracia e a questão do pluralismo. Revista Politica \& Sociedade, Florianópolis, SC, n. 3, out. 2003.

OLIVEIRA, Ozerina Victor. Movimento comutativo da política de currículo: o caso da Escola Sarã. Revista de Educação Pública, Cuiabá, MT, v. 17, n. 33, p. 13-24, jan./abr. 2008. Disponível em: <http://www.ie.ufmt.br/revista/conteudo_33.htm>. Acesso em: 3 dez. 2013.

OLIVEIRA, Ozerina Victoe. Problematizando o significado de reforma nos textos de uma política de currículo. Currículo sem Fronteiras, v. 9, n. 2, p. 68-78, jul./dez. 2009. Disponível em:

<http://www.curriculosemfronteiras.org/vol9iss2articles/oliveira.pdf>. Acesso em: Acesso em: 3 dez. 2013.

SILVA, Ludimila I. A política curricular oficial do Ciclo Básico de Alfabetização Cidadá na rede municipal de ensino de Várzea Grande-MT. Revista Espaço do Currículo, São Paulo, v. 3, n. 1, p. 263-274, mar./set. 2010.

UNESCO. Educação Para Todos: Declaração de Cochabamba. Brasília, DF: UNESCO, mar. 2001a. Disponível em: <http://unesdoc.unesco.org/images/0012/001275/127510por.pdf>. Acesso em: 3 dez. 2013.

UNESCO. Educação Para Todos: o compromisso de Dakar. Brasília, DF: UNESCO; CONSED; Ação Educativa, abr. 2001b. Disponível em: <http://unesdoc.unesco.org/images/0012/001275/127509porb.pdf>. Acesso em: 3 dez. 2013.

VÁRZEA GRANDE. Secretaria Municipal de Educação e Cultura. Plano Municipal de Educação. Várzea Grande - MT: SMEC, 2003.

VÁRZEA GRANDE. Secretaria Municipal de Educação e Cultura. Projeto de Reorganização do Ensino Fundamental e Implantação do Ciclo Básico de Alfabetização Cidadã. Várzea Grande-MT: SMEC, $2004 \mathrm{~b}$.

VÁRZEA GRANDE. Secretaria Municipal de Educação e Cultura. Conselho Municipal de Educação. Resolução no 006/2005/CME/VG. Altera a Resolução 003/2004/CME/VG e dá outras providências. Diário Oficial do Município de Várzea Grande, Várzea Grande, MT, 2005. Disponível em: <http://www.varzeagrande.mt.gov.br/storage/Arquivos/resoluo006de2005.pdf>. Acesso em: 3 dez. 2013. 


\section{Discourse production in a cycle-based curricular policy: the creation of the literacy basic cycle in the municipality of VárzeaGrande - MT}

\section{Abstract}

In this paper the tensions between a cyclebased curriculum and a grade-based curriculum, in Várzea Grande-MT, are problematized. The study aims at understanding the power relations established in processes of production of curricular policies processes, considering antagonistic coexisting curricular organizations. The study is supported on a theoretic-methodological approach which is centrally based in the understanding of curricular policies being constituted in a cyclic movement (BALL, 2001, 2006) and as discourse (LACLAU, 1986, 1996; MOUFFE, 2003). The considerations about a cycle-based curriculum and curriculum politicy are founded in Moreira (1990), Freitas (2003), Lopes (2005), Araújo (2006), Oliveira (2008), Mainardes (2007, 2009), and Silva (2010). The power which permeates the dispute between the cyclebased curriculum - Project CBAC (2004) and the grade-based curriculum is a movement within the curricular policy of the municipality of Várzea Grande. This movement of power allows tensions in the curricular field, in quest for the universality of one single curriculum. The investigation shows that such is a constant quest, what makes it impossible to assert the hegemony of one form of curricular organization, or the other.

Keywords: Curriculum. Discourse. Power relations.
Producción discursiva de una política curricular organizada en ciclos: la creación del ciclo básico de alfabetización en Várzea Grande - MT/Brasil

\section{Resumen}

En este artículo problematizamos la tensión entre el currículo por ciclos y el currículo por serie en el contexto de la política curricular del municipio de Várzea Grande-MT, Brasil. El objetivo del estudio es comprender las relaciones de poder establecidas en procesos de producción de políticas de currículo, considerando la coexistencia de organizaciones curriculares antagónicas. El aporte teóricometodológico que fundamenta el estudio se encuentra pautado en la comprensión de la constitución de la política de currículo en un movimiento cíclico (BALL, 2001 y 2005) y como discurso (LACLAU, 1986 e 1996; MOUFFE, 2003). Las consideraciones sobre currículo organizado por ciclos y política curricular se fundamentan en Moreira (1990), Freitas (2003), Lopes (2005); Araújo (2006), Oliveira (2008), Mainardes (2007 e 2009) e Silva (2010). El poder que permea la disputa entre el currículo organizado por ciclos Proyecto Projeto de Reorganização do Ensino Fundamental e Implantação do Ciclo Básico de Alfabetização Cidadã CBAC (2004) - y el currículo por serie, es un movimiento que acontece en el interior de la política curricular del municipio de Várzea Grande. Ese movimiento, de poder, permite que haya tensiones en el campo curricular buscando apenas, la hegemonía por la universalidad de un único currículo. Lo que esta investigación nos muestra es que esa búsqueda acontece de modo constante, lo que nos imposibilita afirmar la hegemonía de esta o de aquella forma de organización curricular.

Palabras claves: Currículo. Discurso. Relaciones de poder. 
Eucaris Joelma Rodrigues Ferreira

E-mail: eucarisjoelma@hotmail.com

Ozerina Victor de Oliveira

E-mail: ozerina@ufmt.br

Recebido em: 14/02/2014 Aprovado em: 27/02/2015 
